\title{
PEMANFAATAN TANAMAN OBAT KELUARGA SEBAGAI PENGGANTI OBAT KIMIA DI PEDUKUHAN V KUJON LOR, KRANGGAN, GALUR, KULON PROGO, YOGYAKARTA
}

Okimustava, dan mahasiswa KKN

E-mail: okimustava@pfis.uad.ac.id

\begin{abstract}
Abstrak
Toga adalah singkatan dari tanaman obat. Tanaman obat pada dasarnya adalah sebidang tanah baik di halaman, taman, atau lading digunakan untuk menumbuhkan tanaman yang memiliki khasiat obat untuk memenuhi kebutuhan keluarga akan obat-obatan. Taman herbal atau bahan dan kemudian didistribusikan kepada masyarakat, terutama obat yang berasal dari tanaman.
\end{abstract}

Kata kunci: toga, tanaman, obat.

\begin{abstract}
Toga stands medicinal plants. Medicinal plants is essentially a piece of land either in the yard, garden or lading used to cultivate plants that have medicinal properties in order to meet family needs will be drugs. Garden herbs or ingredients and then be distributed to the public, especially drugs derived from plants.
\end{abstract}

Keywords: toga, plants, medicinal.

\section{A. PENDAHULUAN}

Bangsa Indonesia patut bersyukur karena diberi kekayaan alam yang melimpah salah satunya adalah warisan dari nenek moyang berupa ramuan dari tanaman yang bermanfaat bagi kesehatan.

Nenek moyang bangsa Indonesia sejak dulu telah menekuni pegobatan dengan memanfaatkan aneka tanaman yang terdapat di alam. Warisan yang berharga ini secara turun temurun diajarkan dari generasi ke generasi selanjutnya. Di daerah pedesaan, tradisi ini sebagian besar masih di pertahankan. Namun, masyarakat perkotaan lebih memilih cara praktik yaitu pergi ke dokter jika sakit.

Semakin berkembangnya jaman maka semakin meningkatnya pengetahuan manusia tentang ilmu kedokteran dan penelitian oleh para profesor, sehingga banyak masyarakat yang beralih pada obat - obatan dokter karena mereka lebih mempercayai obat - obatan kimia yang telah teruji khasiatnya secara laboratorium dan teruji klinis.

Akan tetapi seiring berjalannya waktu, kehidupan berubah. Dengan adanya krisis moneter yang dialami Indonesia, masyarakat terdorong dengan kembali menggunakan obat - obatan tradisional yang boleh dikatakan bebas dari komponen impor, terutama bebas dari bahan - bahan kimia yang kemungkinan dapat berakibat fatal bagi kesehatan tubuh.

Penduduk yang berada di Pedukuhan V Kujon Lor telah lama memanfaatkan tanaman obat keluarga untuk alternatif obat-obatan. Bahkan ada kelompok yang dinamakan KWT yang melakukan penanaman tanaman obat didepan rumah atau lingkungan rumah. 


\section{Metode Penelitian}

\begin{tabular}{|c|c|}
\hline Kegiatan & Hari ke- \\
\hline Persiapan Penyuluhan & \\
\hline Perijinan & \\
\hline Persiapan alat dan bahan & \\
\hline Pelaksanaan penyuluhan & \\
\hline
\end{tabular}

\section{B. METODE PELAKSANAAN}

Metode pelaksanaan program ini melalui tahapn sebagai berikut:

1. Perizinan

Perizinan adalah faktor yang sangat penting guna memperlancar jalannya penyuluhan yang diadakan. Selain itu, merupakan suatu syarat legalitas apabila kita melakukan kegiatan di suatu lokasi tertentu.

2. Proses perizinan

Proses perizinan dimulai dengan pembuatan surat izin akan diadakannya penyuluhan yang ditujukan untuk para warga di pedukuhan V Kujon Lor, Kranggan, Galur, Kulon Progo. Surat izin berisi uraian dari kegiatan penyuluhan tersebut, dari latar belakang, rumusan masalah, tujuan, dan waktu dari kegiatan penyuluhan.

3. Persiapan alat dan bahan

Persiapan alat dan bahan dilakukan agar proses penyediaan tanaman toga dapat berjalan lancar.

4. Pelaksanaan penyuluhan

Penyuluhan dilakukan setelah tahap-tahap pelaksanaan diatas.

Estimasi waktu 400 menit dalam dua hari.

\section{GAMBARAN TEKNOLOGI}

Toga adalah singkatan dari tanaman chat keluarga. Taman obat keluarga pada hakekatnya sebidang tanah baik di halaman rumah, kebun ataupun ladang yang digunakan untuk membudidayakan tanaman yang berkhasiat sebagai obat dalam rangka memenuhi keperluan keluarga akan obat-obatan. Kebun tanaman ohat atau bahan ohat dan selanjutnya dapat disalurkan kepada masyarakat, khususnya obat yang berasal dari tumbuh-tumbuhan.

Dalam pelaksanaanpenyediaan toga ini dibutuhkan beberapa alat dan bahan seperti polybag, tanah, kotoran kambing, abu sekam, sendok semen dan tanaman toga itu sendiri yang terdiri dari tanaman temu ireng, tamulawak, sirih merah, kumis kucing, kunyit dan cabai jawa.

Penyediaan tanaman toga di pedukuhan Kujon Lor ini bertujuan agar bisa memenuhi keperluan kebutuhan masyarkat akan pentingnya tanaman obat keluarga (TOGA) sebagai media obat tradisional yang dapat dikembangkan oleh masyarakat itu sendiri.

Pembuatan untuk penyediaan tanaman obat keluarga (TOGA) dimulai dengan menyediakan kotoran kambing dan abu sekam sebagai kompos alami, kemudian dicampurkan secara rata dengan tanah dan dimasukkan kedalam polybag tanam. Masukkan 
Diterbitkan oleh Lembaga Pengabdian kepada Masyarakat

Universitas Ahmad Dahlan Yogyakarta

bibit tanaman toga yang yang disiapkan sebelumnya kedalam polybag tersebut. Setelah melalui proses diatas maka penyediaan TOGA untuk pedukuhan Kujon Lor.

\section{MEDIA PENYULUHAN}

Media yang digunakan dalam penyuluhan ini adalah media presentasi. Mediapresentasi ini digunakan untuk mejelaskan secara teoritis bagaimana pembuatan untuk penyediaan tanaman toga. Selanjutnya dilakukan demonstrasi bertujuan untuk menjelaskan bagaimana pemanfaatan tanaman obat keluarga (TOGA).

\section{E. HASIL, PEMBAHASAN DAN DAMPAK}

Toga adalah singkatan dari tanaman obat keluarga. Tanaman obat keluarga pada hakekatnya sebidang tanah baik di halaman rumah, kebun ataupun lading yang digunakan untuk membudidayakan tanaman yang berkhasiat sebagai obat dalam rangka memenuhi keperluan keluarga akan obat-obatan. Kebun tanaman obat atau bahan obat dan selanjutnya dapat disalurkan kepada masyarakat, khususnya obat yang berasal dari tumbuh-tumbuhan.

Untuk memperoleh pengobatan yang ideal seorang pengobat herbal harus pandai dan cermat dalam membuat formula tanaman obat. Formula yang digunakan dalam pengobatan haruslah sesuai dengan kondisi pasien yang berobat.kondisi pasien sangat berkaitan dengan dosis dan tingkat keberhasilan dalan pengobatan herbal.

Tanaman obat keluarga pada dasarnya adalah tanaman yang ditanam di halaman rumah, kebun ataupun sebidang tanah yang dimanfaatkan sebagai budidaya tanaman yang berkhasiat sebagai obat dalam rangka memenuhi kebutuhan keluarga akan obat-obatan. Tanaman obat keluarga juga berfungsi sebagai pemanfaatan lingkungan di sekitar rumah dan kebun. Di era sekarang semakin banyak keluarga yang sadar betul apa manfaat dari tanaman obat itu sendiri.

Galur adalah sebuah kecamatan di kabupaten Kulon Progo, Provinsi Daerah Istimewa Yogyakarta (DIY), Indonesia. Lokasinya terletak di sebelah selatan Kabupaten Bantul. Kecamatan Galur di daerah Kabupaten Kulon Progo adalah salah satu daerah yang mayoritas penduduknya bermata pencaharian sebagai petani dan peternak, namun karena akhir-akhir ini bertambahnya lahan kerja yang berada di kecamatan tersebut, sehingga jelas mempengaruhi terhadap kehidupan bersosiali di sana terutama generasi muda jarang yang mau turun ke sawah. Namun tidak semua masyarakat yang menggantungkan hidup pada sawah ataupun ternak, ada juga yang berwirausaha. Potensi yang berada di Galur sangat besar, sehingga akan memungkinkan untuk digunakan sebagai lahan tanaman obat yang dapat digunakan sebagai obat-obatan. 

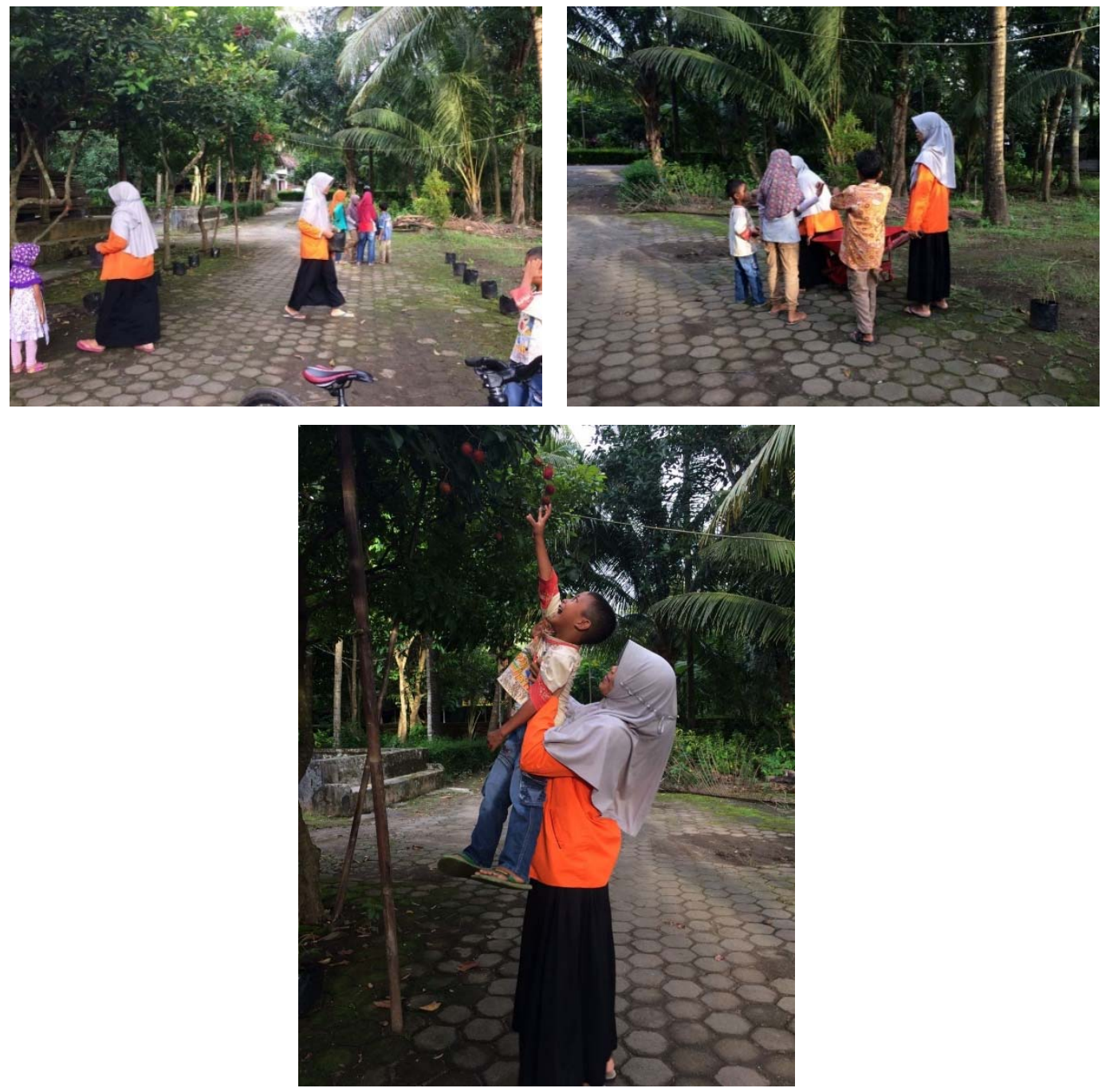

Gambar 1. Aktifitas KKN Mahasiswa

\section{F. KESIMPULAN}

Berdasarkan uraian diatas dapat disimpulkan bahwa TOGA (Tanaman obat keluarga) merupakan upaya untuk meningkatkan pemanfaatan tanaman berkhasiat obat. Selain sebagai sarana untuk menjaga kesehatan masyarakat, toga juga berfungsi sebagai sarana penghijauan, sarana untuk pelestarian alam, sarana memperbaiki gizi, sarana untuk pemerataan pendapatan, sarana penyebaran gerakan penghijauann dan sarana keindahan pekarangan atau lingkungan. 
Diterbitkan oleh Lembaga Pengabdian kepada Masyarakat

Universitas Ahmad Dahlan Yogyakarta

\section{DAFTAR PUSTAKA}

Departemen Kesehatan RI. Tanaman Chat Keluarga Edisi III. Jakarta 1983.

Departemen Kesehatan RI. Pemanfaatan Tanaman obat Edisi III, Jakarta. 1983.

Departemen Kesehatan RI. Misteri Modika Indonesia Jilid I dan II. Jakarta 1983.

Departemen Kesehatan RI. Pemanfaatan Tanaman Obat. Jakarta 1992. 